\title{
MULHERES ENCARCERADAS: DIFICULDADES VIVENCIADAS ANTES, DURANTE E APÓS A PRISÃO
}

Tatiana Cavalcanti de Albuquerque Leal ${ }^{1}$ Anielle Oliveira Monteiro ${ }^{2}$

Resumo: Reiteradas estatísticas revelam um perfil bastante comum da população carcerária feminina: mulheres jovens, solteiras, não brancas, com baixa escolaridade e que cometeram crimes relacionados ao tráfico de drogas. Muitas vieram de contextos de violência prévios e a prisão se encaixa como mais um elo na cadeia de violências vivida. Este ciclo da violência se inicia na família e nas instituições para crianças e adolescentes, continua no casamento, desdobra-se na ação tradicional das polícias e finaliza na penitenciária. Isto porque a múltipla penalização na prisão ultrapassa a pena de reclusão, abarcando castigos corporais, ambientes insalubres, exposição às drogas, contágio de várias doenças e abandono familiar. Assim, o objetivo deste artigo foi conhecer quais foram as maiores dificuldades vivenciadas antes, durante e após o cárcere para mulheres já em livramento condicional. Trata-se de uma análise documental de pareceres psicossociais de mulheres realizados entre junho de 2013 e junho de 2014 na Vara de Execuções Penais do Fórum Criminal de João Pessoa/PB. Foram encontrados 12 pareceres, analisados por meio da técnica de análise de conteúdo de Bardin. As dificuldades vividas antes do cárcere foram categorizadas como "Abandono parental”, "Trabalho precoce”, "Doenças crônicas na infância/adolescência”, "Abuso sexual", "Relacionamentos abusivos" e "Aliciamento ao crime por figuras masculinas”. Durante o cárcere, as dificuldades encontradas foram "Solidão" e "Estratégias de resistência". Depois da prisão, os problemas foram classificados em "Saúde comprometida"

\footnotetext{
${ }^{1}$ Mestra e doutoranda em Psicologia Social pela Universidade Federal da Paraíba. Graduada em Psicologia e graduanda em Direito pela Universidade Federal da Paraíba. Atua principalmente nas áreas de Direitos Humanos, Psicologia Social e Psicologia Jurídica

${ }^{2}$ Mestra em Direitos Humanos, Cidadania e Políticas Públicas pela Universidade Federal da Paraíba e doutoranda em Ciências Jurídicas pela Universidade Federal da Paraíba. Graduada em Direito pela Universidade Estadual da Paraíba. Atua principalmente nas temáticas de Direitos Humanos, Gênero e Diversidade
} 
e "Dificuldade financeira ou de inserção no mercado de trabalho". O conjunto dos resultados revelou, de fato, histórias atravessadas por vulnerabilidades sociais e um ciclo de violências que pode começar com o abandono pelos pais na infância, passando por abusos diversos, aliciamento ao crime por homens próximos e penalizações adicionais no cárcere, e terminar com a condição socioeconômica precária e exclusão do mercado de trabalho depois da prisão.

Palavras-chave: Mulheres. Cárcere. Dificuldades. Trajetórias de vida.

Abstract: Repeated statistics reveal a fairly common profile of the female prison population: young, single, nonwhite, low-schooling women, who have committed drug-related crimes. Many have come from previous contexts of violence and the prison fits as another link in this chain of violence experienced. This cycle of violence begins in the family and institutions for children and adolescents, continues in marriage, unfolds in the traditional action of the police and ends in prison. That is because the multiple penalization in prison exceeds the penalty of
152

imprisonment, including corporal punishment, unhealthy environments, exposure to drugs, contagion of various diseases and family abandonment. Thus, the aim of this article was to know which were the greatest difficulties experienced before, during and after jail for women already on probation. It's a documentary analysis of psychosocial documents of women carried out between June 2013 and June 2014 in the Court of Criminal Executions of the Criminal Forum of João Pessoa/PB. Twelve documents were found, analyzed using the technique of content analysis by Bardin. The difficulties experienced before the imprisonment were categorized as "Parental Abandonment," "Early Work," "Childhood/Adolescence Chronic Illness," "Sexual Abuse," "Abusive Relationships," and "Enticement to Crime by Male Figures." In jail, the difficulties encountered were "Solitude" and "Strategies of resistance". After their release, the problems were classified in "Health problems" and "Difficulty in financial or labor market insertion". The set of results revealed, in fact, histories crossed by social vulnerabilities and a cycle of violence that can begin with the abandonment by the parents in the 
childhood, going through diverse abuses, being enticed to crime by close men and suffering additional penalties in jail, and ending with precarious socioeconomic conditions and exclusion from the labor market after imprisonment.

Keywords: Women. Prison.

Difficulties. Life trajectories.

\section{Introdução}

O atual modelo prisional não foi desenvolvido para aprisionar mulheres (Buglione, 2007). Isso é facilmente percebido ao notar-se que, para atendêlas e, sobretudo, para adaptar-se às suas especificidades, atualizações arquitetônicas - como a criação de creches - precisaram ser feitas nos presídios. Este fator, inclusive, revela como esta instituição reforça o padrão cultural de que a tarefa de cuidar da prole é quase que exclusivamente feminina, uma vez que, até então, não foi verificada a existência de creches em penitenciárias masculinas (Cortina, 2015).
Apesar da (pouca) adaptação dos presídios para encarcerá-las, a quantidade de mulheres presas no Brasil é muito inferior à quantidade de homens presos. Os dados do último relatório do Infopen (Santos, 2017), referente a levantamento de 2016, revelam que havia 689.947 pessoas privadas de liberdade no sistema prisional no país neste ano, sendo 41.987 mulheres (6\%) e 648.860 homens (94\%).

Diferentes interpretações destes quantitativos surgem a fim de explicar a menor incidência da criminalidade feminina. Uma das mais populares, inclusive no inconsciente coletivo, é a biológica, perpetuada, por exemplo, por Lombroso e Ferreiro (2004). Fausto (2001) contesta os estudos que apontam fatores biológicos das mulheres como determinantes para a menor incidência delas no crime, defendendo que a sua presença na criminalidade é, também, uma consequência da redução da desigualdade entre os sexos, ao menos no âmbito da sociedade ocidental, que vai gerar maior presença da mulher tanto no trabalho fora de casa como em diversos campos, inclusive o da criminalidade. 
Não obstante estas tentativas de explicações para a maior incidência de criminalidade entre os homens do que entre as mulheres, é importante ressaltar que houve um aumento de $656 \%$ na taxa de encarceramento de mulheres no Brasil entre 2000 e 2016, enquanto que, neste mesmo período, a população carcerária masculina cresceu 293\% (Instituto Igarapé, 2019).

Naturalmente, a maioria das mulheres que são privadas de liberdade atendem a um perfil bastante específico. Reiterados dados de pesquisas vão revelando uma descrição comum da população carcerária feminina: mulheres jovens (com média de idade de 30 anos), solteiras, não brancas, com baixa escolaridade e com histórico de ruptura de vínculos familiares (Carvalho et al., 2006; Cerneka, 2009; Shamai e Kochal, 2008).

De modo geral, a realidade social das pessoas que estão aprisionadas é normalmente perpassada por um histórico de educação deficitária, infração juvenil, uso de drogas e envolvimento com o tráfico. Para as mulheres, especificamente, sobressaemse também histórias prévias de violência, de abandono e de cooptação por homens criminosos (Carvalho et al., 2006; Huang et al., 2012). A maioria das detentas, neste contexto, vem de camadas socioeconomicamente empobrecidas da população, tomando-se em consideração o baixo grau de escolaridade, as vulnerabilidades relatadas e suas ocupações antes de serem presas: ajudante de feirante, auxiliar de serviços gerais, domésticas e faxineiras (Frinhani e Souza, 2005).

Apesar da constatação, é necessário não relacionar, diretamente, criminalidade com classe socioeconômica baixa, o que somente reforça o estigma de violenta e perigosa imposto a ela. Fato é que a população carcerária não é uma amostra representativa do conjunto total de infratores (Frinhani e Souza, 2005). O sistema penal age de maneira seletiva, elegendo a clientela prisional por meio de critérios definidos cultural e economicamente, de acordo com sua função de controle social penal (Cortina, 2015), o que pode ser percebido quando verifica-se a grande desproporção existente entre a programação legal do sistema penal, constituída de inúmeros tipos penais, e a capacidade operacional das agências de controle penal para 
perseguir e punir os agentes que cometem as condutas definidas como crime, a qual é muito inferior ao universo de crimes praticados (Zaffaroni, 1991).

De fato, apenas três crimes (roubo, furto e tráfico de drogas), juntos, são a causa de $65 \%$ dos aprisionamentos no Brasil (Santos, 2017). Há uma infinidade de outros tipos penais que foram praticados, mas que não se juntam a esta estatística. Ou seja, elegem-se alguns crimes como prioritários e merecedores do cárcere, os quais, não coincidentemente, estão normalmente ligados a um perfil específico de pessoas (Cortina, 2015).

Baratta (2002) afirma que isso ocorre por que as malhas do sistema penal são entrelaçadas de maneira bastante rigorosa quando se trata de crimes que atentam contra os interesses das classes dominantes, como os crimes contra o patrimônio, e, em contraposição, de forma frouxa quando se refere a outro tipo de criminalidade, cuja clientela é, em regra, isenta de punição. Sob esta perspectiva, a prisão não seria uma instituição falida, mas sim extremamente funcional na tarefa de selecionar e encarcerar a população que se encontra na marginalidade social.
No caso das mulheres, como evidenciam os dados do Infopen (Santos, 2017), a seletividade penal recai mais expressivamente sobre o crime de tráfico de drogas. Enquanto que os crimes ligados ao tráfico representam $26 \%$ dos registros dos homens privados de liberdade, entre as mulheres tal percentual atinge $62 \%$ dos crimes tentados ou consumados. É por tráfico de drogas que a maioria das mulheres vai presa no Brasil.

A participação e presença da mulher no tráfico ainda suscita certa estranheza. Existe, segundo Assis e Constantino (2001), um imaginário social construído em torno da criminalidade feminina que é acolhido inclusive por juízes, delegados, carcereiros, advogados e demais autoridades do sistema jurídico-penal. De acordo com esta concepção, de forma bastante lombrosiana, as mulheres seriam fortemente influenciadas por estados fisiológicos e seus crimes seriam, em sua maioria, cometidos dentro do espaço privado. As mulheres se envolveriam mais em crimes cometidos sob violenta emoção.

Ainda conforme essa perspectiva, quando as mulheres 
cometem crimes de outra natureza, como a participação no tráfico de drogas, esses só poderiam estar atrelados a uma posição subalterna da mulher, justificada como uma extensão natural de suas relações afetivas. Isto apenas não se aplicaria quando se tratando de lésbicas ou prostitutas, que são identificadas como mais parecidas com os homens, mais "masculinizadas" e habituadas à rua e à delinquência (Assis e Constantino, 2001).

Apesar de existir um aliciamento ou forte influência de companheiros e demais figuras masculinas para envolver-se com o tráfico de drogas, a crescente participação feminina na atividade não se explica apenas por este fator (Barcinski, 2009). Para algumas mulheres, o envolvimento com tal crime foi deliberadamente assumido, um ato de escolha pessoal, com frequência para obter reconhecimento e status social.

Dados coletados na pesquisa de Cortina (2015), feita com mulheres em situação de prisão, evidenciaram que os motivos por elas mais relatados para escolherem o envolvimento com a traficância ilegal são as dificuldades em sustentar os filhos e filhas e a falta de inserção no mercado de trabalho lícito e formal. Considerando que tal crime é muito lucrativo em comparação com a remuneração ofertada pelas ocupações lícitas destinadas a pessoas com baixa escolaridade, além de permitir a boa parte das mulheres trabalhar em casa, o tráfico de drogas apresenta-se como alternativa viável para que elas possam aliar o trabalho com o cuidado dos filhos. Apesar de tais considerações sobre um protagonismo feminino na atividade, merece destaque o papel de figuras masculinas nas práticas criminosas pelas quais as mulheres estão presas. Frinhani e Souza (2005) mostraram que, em suas entrevistas com mulheres presas, de uma forma ou de outra, as entrevistadas se referiam a algum homem como sendo $\mathrm{o}$ responsável, quer direta ou indiretamente, pelo seu ingresso na criminalidade ou mesmo pela prisão.

Muitas das mulheres que são aprisionadas vieram de um contexto de violências dentro de uma realidade bastante comum que inclui, além de agressões físicas, sexuais e psicológicas, também perdas violentas de parentes próximos e/ou de parceiros conjugais (Guedes, 2006). Ocorre que, no sistema penitenciário, a violência social continua 
a ser refletida por meio dos presídios superlotados, celas pouco arejadas e com insalubridade, precária assistência médica, educacional, social e jurídica, etc. (Soares et al., 2014).

Neste sentido, Soares e Ilgenfritz (2002) afirmam que a prisão, tanto pela privação de liberdade em si quanto pelos abusos que ocorrem em seu interior, parece ser só mais um elo na cadeia de múltiplas violências que compõem a trajetória de uma parte da população feminina. Esse ciclo da violência, que tem início na família e nas instituições para crianças e adolescentes, continua no casamento, desdobra-se na ação tradicional das polícias e finaliza na penitenciária, para tornar a ser iniciado, provavelmente, na vida delas quando saírem da prisão.

Embora quantitativamente bem menos numéricas nas prisões, existem evidências de que a experiência na prisão produza danos diferentes e, inclusive, mais significativos nas mulheres do que nos homens, em especial por conta da própria estrutura familiar e da posição da mulher na sociedade e no mercado de trabalho. $\mathrm{O}$ aprisionamento representa a quebra de vínculos familiares e pessoais, a deterioração da identidade feminina e o cumprimento de mais uma etapa de um ciclo de violências sofridas, presenciadas e praticadas na vivência das mulheres (Soares e Silva, 2002).

Nas prisões, há uma múltipla penalização imposta aos detentos e detentas. Além da própria privação da liberdade, ocorrem também castigos corporais, a exposição às drogas e ao contágio de várias enfermidades (Souza et al., 1998). Também, como penalizações adicionais, é frequente que recebam menos visitas que os homens, o que gera um sentimento de abandono e solidão (Carvalho et al., 2006; Cerneka, 2009). Por isso, muitas relatam valorizar mais o convívio com a família depois de presas (Guedes, 2006). Enquanto a média de visitas por mulher presa foi de 5,9 no intervalo de um semestre no ano de 2016, a de homens foi de 7,8 (Instituto Igarapé, 2019).

É importante salientar que a ausência de privacidade e os modos próprios do sistema carcerário leva os agentes públicos e a sociedade a tratar os familiares da mesma forma com que tratam aqueles que de fato cumprem a pena. É neste sentido que se insere a invasiva e inadequada revista aos familiares nas visitações, de modo que, 
assim, estes também cumpririam uma espécie de pena, além de a revista não garantir óbice efetivo àquilo que se quer evitar (Fiorelli e Mangini, 2017). O vexame da revista é um obstáculo às visitações e contribui para a solidão na prisão.

Neste contexto, a violência incorpórea representada pelas práticas disciplinadoras da instituição prisão atua no sentido de tentar anular as vontades e os desejos pessoais (Fonseca, 2006). Em resposta, no dia-a-dia, percebem-se práticas sociais que as mulheres produzem como um modo de resistência ao controle de seus corpos, desejos, subjetividade, e como modo de produzir vida e inventar saúde (Soares et al, 2014).

As estratégias de resistência e visibilização no cárcere, para as mulheres privadas de liberdade, vão desde a forma com que as apenadas procuram se maquiar e arrumar o cabelo, o que atenua a despersonalização e uniformização promovida pela instituição prisional (Cunha, 1994; 1996), até aspectos relacionados às formas de se relacionarem entre si estabelecidas dentro da prisão, onde ocorre uma espécie de reedição de relações afetivas filiais, maternais ou fraternais entre as mulheres presas (Barcinski, 2012).

Segundo Gonçalves e Madrid (2010), a religião também tem exercido um papel importante na prisão. Em um cotidiano de privação de liberdade, marcado pela violência, as atividades religiosas vêm a oferecer uma oportunidade de ressignificação da trajetória de quem está preso ou presa. Guimarães et al (2006: 54) lembram que a religião de fato evidencia uma "possível transformação ocorrida com o preso, podendo servir como redutor da penalidade e obtenção de benefícios jurídicos para o apenado, embora possa significar a passagem de um tipo de controle social para outro".

Uma das estratégias de resistência utilizadas é também o estudo dentro do cárcere, que é, ao mesmo tempo, uma estratégia de "tratamento" prevista para a delinquência. $\mathrm{O}$ ensino dentro do sistema prisional, especialmente o profissionalizante, como diz Baratta (1999), tem destinações específicas para a população feminina carcerária, tendo a finalidade de reproduzir e assegurar, no caso das mulheres proletárias, a sua dupla 
subordinação, tanto nas relações de gênero como nas relações de produção, e a manutenção de sua classe socioeconômica. Contudo, a busca pela educação surge como uma porta para possibilidades futuras para aquelas mulheres presas.

Pensar nos projetos futuros póscárcere também é uma forma de resistir. Geralmente, quando tentam vislumbrar planos de vida futuros, as detentas desejam recomeçar a vida e iniciar ou retomar atividades como cuidar dos filhos, estudar, afastar-se do mundo das drogas e trabalhar, mesmo tendo ciência de que terão dificuldades em encontrar um trabalho devido ao estigma de expresidiárias (Guedes, 2006).

Uma vez em liberdade, a pessoa que foi privada de liberdade se depara com uma série de dificuldades na inserção no mercado de trabalho devido ao estigma e ao preconceito por tal condição, e pouca ou nenhuma perspectiva de emprego lhe é dada. A situação se agrava ainda mais para as mulheres. $\mathrm{O}$ estigma por elas enfrentado é maior, pois teriam fugido mais do que os homens aos padrões impostos socialmente, como servir ao marido e aos filhos e atender ao papel de "do lar". Se as oportunidades de emprego para elas já poderiam ser escassas antes do encarceramento, depois são ainda mais. Poucas conseguem o "perdão social" e direito de voltar a participar da sociedade civil (Rosendo et al., 2018).

Embora, no Brasil, haja uma produção significativa de pesquisas na área da criminalidade feminina, elas se referenciam, em geral, à vida pregressa das mulheres encarceradas e o cotidiano prisional, enquanto que detalhes da vida após o cárcere são mais escassos. Neste sentido, o presente artigo teve como objetivo conhecer quais foram as maiores dificuldades vivenciadas antes, durante e após o cárcere para mulheres egressas do sistema prisional, mas ainda em livramento condicional.

\section{Método}

Esta pesquisa se trata de uma análise documental das entrevistas psicossociais completas de mulheres em livramento condicional, constantes do conjunto dos autos processuais das mesmas, realizadas entre junho de 2013 e junho de 2014 na Vara de Execuções Penais do Fórum Criminal da cidade de João Pessoa/PB. 
Neste intervalo de um ano, foram encontrados pareceres psicossociais de 12 mulheres em livramento condicional. Nestes pareceres, havia breves histórias de vida e considerações sobre a vida atual das entrevistadas, então em livramento condicional, o que tinha como fim monitorar a liberdade das mesmas.

Neste sentido, a presente pesquisa se aproximaria também da técnica de histórias de vida, que apresenta as experiências e as definições vividas por uma pessoa, um grupo, uma organização, como esta pessoa, esta organização ou este grupo interpretam sua experiência (Denzin, 2017). Bourdieu (1973, apud Minayo, 2004) nos lembra ainda que a história do indivíduo é sempre uma certa especificação da história coletiva de seu grupo e sua classe.

O conjunto das entrevistas foi analisado com base na técnica de análise de conteúdo categorial temática de Bardin (2011), e os dados descritivos da amostra foram calculados por meio do software SPSS - Statistical Package for Social Sciences, em sua versão 23. Na categorização de Bardin (2011), reúnemse em categorias (rubricas ou classes com um título genérico) unidades de texto (como frases) que têm algo em comum segundo o critério usado (neste caso, o semântico). O processo de categorização torna-se, de tal modo, uma representação simplificada do todo bruto.

\section{Resultados}

Os pareceres coletados revelaram que a média de idade das mulheres da amostra foi de 41,5 anos (DP=11,6), com idades variando de 27 a 69 anos. A maioria delas cumpriu pena por condenação a crimes relacionados a tráfico de drogas $(41,7 \%)$ ou homicídio $(33,3 \%)$, e, em menor quantidade, roubo $(16,7 \%)$ e perigo de contágio de moléstia grave $(8,3 \%)$. Seis mulheres $(50 \%)$ tinham ensino fundamental incompleto, cinco tinham ensino médio completo $(41,7 \%)$ e uma delas tinha ensino superior e pós-graduações $(8,3 \%)$.

Das doze mulheres da amostra, cinco $(41,7 \%)$ tinham realizado algum curso técnico ou de capacitação profissional enquanto estiveram presas. Os cursos eram nas áreas de artesanato, corte e costura, culinária e informática. No que diz respeito ao estado 
ocupacional após o cárcere, quando em livramento condicional, três liberadas (25\%) estavam desempregadas, duas estavam aposentadas $(16,7 \%)$ e as demais sete $(58,2 \%)$ estavam trabalhando, formal ou informalmente.

Por meio da análise de conteúdo realizada nos pareceres, foram feitas categorizações para cada um dos períodos da vida das mulheres da amostra de documentos usada que se queria abarcar: antes, durante e póscárcere. A técnica utilizada foi a de análise categorial temática de Bardin (2011), a partir da presença ou ausência do tema que se analisava dentro dos textos e do critério semântico.

$\mathrm{Na}$ Tabela 1, visualiza-se a relação das categorias temáticas criadas.

\begin{tabular}{l|c|c}
\hline Categorias & $\mathbf{N}$ & $\mathbf{P}$ \\
\hline Antes & & \\
\hline Abandono parental & 5 & $41,6 \%$ \\
\hline Trabalho precoce & 3 & $25 \%$ \\
\hline Doenças crônicas na infância/adolescência & 2 & $16,6 \%$ \\
\hline Abuso sexual & 2 & $16,6 \%$ \\
\hline Relacionamentos abusivos & 3 & $25 \%$ \\
\hline Aliciamento ao crime por figuras masculinas & 3 & $25 \%$ \\
\hline Durante & & \\
\hline Solidão & 3 & $25 \%$ \\
\hline Estratégias de resistência & 5 & $41,6 \%$ \\
\hline Depois & & \\
\hline Saúde comprometida & 5 & $41,6 \%$ \\
\hline Dificuldade financeira ou de inserção no mercado de trabalho & 4 & $33,3 \%$ \\
\hline
\end{tabular}

Tabela 1- Detalhamento das categorias antes, durante e depois do cárcere, resultantes da análise de conteúdo categorial temática.

Uma vez apresentadas as categorias criadas, será feita uma descrição de seus conteúdos, bem como a apresentação dos discursos escolhidos como mais representativos/ilustrativos delas. 
Antes do cárcere

As referências a vivências ou dificuldades anteriormente ao cárcere encontradas nos registros foram maioria. Foi incluído como vivências antes da prisão tudo o que foi registrado no parecer de cada egressa e que dizia respeito a adversidades no período anterior ao cárcere, cobrindo um espectro que vai de informações da infância até dados sobre a vida imediatamente antes do aprisionamento.

A categoria "Abandono parental" foi a mais recorrente ( 5 de 12 mulheres relataram a criação sem um dos pais ou ambos) deste grupo e traz as experiências de abandono pelo pai ou pela mãe (embora somente um caso tenha sido de abandono materno) sofridas na infância ou adolescência. Por exemplo, tem-se o parecer I, que relata “(...) Foi criada pela mãe e por diferentes padrastos (...) seu pai biológico nunca exerceu papel de pai, não se importando muito com ela e as irmãs” e o parecer K: “(...) Só conheceu a mãe aos 15 anos, tendo sido criada pelo pai e por uma madrasta que era um pouco agressiva (...) a mãe biológica nunca a aceitou e teve com ela uma relação maternal".

A classe "Trabalho precoce", por sua vez, agrupou todos os trechos dos pareceres em que havia menção a trabalhos ou atividades laborais realizadas na infância e/ou adolescência, sendo que todos foram trabalhos domésticos (dois de babá e um de empregada doméstica). São representativos desta categoria, assim, as passagens: "Aos catorze anos de idade, fugiu de casa para seguir a profissão da mãe [empregada doméstica]" (Parecer D) e “(...) desde os 10 anos começou a trabalhar como babá, o que a impedia de vivenciar sua infância plenamente, como brincar e ir à escola" (Parecer J).

A categoria "Doenças crônicas na infância/adolescência" surgiu para acomodar os relatos sobre enfermidades desse caráter quando aquela mulher era criança ou adolescente, tendo sido um caso de epilepsia e outro caso de asma. Diz o parecer G “(...) a partir dos 14 anos, foi diagnosticada com epilepsia, quando passou a apresentar algumas convulsões e a fazer uso de medicamentos anticonvulsivantes (...)" e o parecer E “(...) desenvolveu asma aos 4 anos de idade, doença que, segundo a 
entrevistada, marcou toda a sua vida negativamente (...)".

Em “Abuso sexual”, por sua vez, foram colocados os trechos dos pareceres em que havia relatos desta forma de abuso, sendo um abuso praticado pelo padrasto e o outro não declarada a autoria. Neste sentido, o parecer E: "Possui cinco filhos, sendo um deles fruto de um estupro" e o parecer I: “(...) chegou a ser abusada por um de seus padrastos quando tinha 11 anos".

Já na categoria "Relacionamentos abusivos", foram colocados os trechos que expressavam a vivência em relacionamentos afetivos com maridos ou companheiros abusivos. Ilustram o teor desta categoria o relato presente no parecer $\mathrm{H}$ : “(...) O ciúme, o desprezo e as agressões sofridas perpetradas pelo ex-marido, a quem cometeu homicídio" e no parecer J: (...) separou-se porque o companheiro bebia muito e queria agredi-la".

Por fim, na categoria "Aliciamento ao crime por figuras masculinas" estão todos os trechos que referiam que, para o crime pelo qual aquelas mulheres foram condenadas, elas foram aliciadas por algum homem de seu convívio familiar. É importante salientar que, do total de cinco crimes relacionados ao tráfico de drogas, em três, ou seja, $60 \%$, as mulheres foram a eles aliciadas pelos seus companheiros ou parentes - em dois casos pelos companheiros e em um caso pelo irmão.

Podem ser usados para representar o tema desta categoria os trechos do parecer G, que traz “(...) Entende que o amor pelo irmão motivoua a fazer o favor que ele a pedira, que foi o roubo" e do parecer B, no qual encontra-se “(...) Hoje viúva de um esposo que foi dito responsável por envolvê-la com o tráfico (...) disse ter feito isso para defendê-lo e livrá-lo de mais uma acusação, pois ele já tinha muitas e já havia sido preso".

\section{Durante o cárcere}

No que concerne ao tempo no cárcere, foram incluídos nestas classes os relatos que aludiam à vida e ao dia-a-dia das mulheres entrevistadas dentro da prisão, tendo sido encontradas apenas informações que se referiam a duas circunstâncias: solidão ou resistências.

Na primeira categoria, "Solidão", foram reunidos os relatos sobre ter sido 
ISSN | 2179-7137 | http://periodicos.ufpb.br/ojs2/index.php/ged/index

vivenciado tal sentimento de forma acentuada quando estas mulheres estavam encarceradas, devido a ausência de visitas dos parentes, cônjuges/companheiros, ou mesmo em decorrência da falta de amizades com as colegas do local, tais como os relatos do parecer C, que revela "Em seu período de reclusão, diz ter sido muito solitária. Não se relacionava muito com as outras colegas de cela e mal saía para tomar banho de Sol, assim como também não recebia visitas" e do parecer $\mathrm{J}$, "Enquanto estava reclusa, passava a maior parte do tempo sozinha e referiu que chorava bastante".

$\mathrm{Na}$ categoria "Estratégias de resistência", estão todos os trechos dos pareceres que informavam as estratégias de resistência utilizadas por aquelas mulheres privadas de liberdade para continuar sobrevivendo com saúde à reclusão. Em geral, essas estratégias foram a aproximação com a religião, o desempenho de alguma atividade laboral dentro da prisão ou a realização de cursos profissionalizantes que eram oferecidos.

Neste sentido, o parecer E, que traz “(...) Na prisão, evangelizou-se e fez disso o seu novo modo de vida e ocupação", e o parecer D: "Quando presa, afirmou que buscou não desenvolver problemas de relacionamento e sempre se ocupar, fazendo cursos, como os que fez de corte e costura de moda praia e preparo de doces e salgados, e trabalhando, de modo que trabalhou na horta, na cozinha e na limpeza".

\section{Depois do cárcere}

Por fim, nas dificuldades vividas após a conquista da liberdade foram descobertas duas informações: sobre os efeitos na saúde ou sobre a precariedade financeira ou exclusão do mercado de trabalho. Foram reunidas na primeira categoria as informações registradas sobre problemas de saúde físicos e mentais com os quais as mulheres passaram a sofrer depois que adquiriram a liberdade, algumas vezes decorrentes da própria vida na prisão. Por isso, esta é uma classe que também diz respeito, em alguma medida, à vida durante o cárcere. Chama a atenção a incidência significativa: 5 das 12 mulheres, ou seja, $41,6 \%$, relataram comprometimentos na saúde depois de passar pelo cárcere. 
ISSN | 2179-7137 | http://periodicos.ufpb.br/ojs2/index.php/ged/index

Ilustram o teor da classe "Saúde comprometida" os trechos “(...) Tendo ficado com uma série de problemas psicossociais por conta desta prisão, como sintomas de ansiedade, depressão e uma forte insônia, além de problemas de saúde como a tuberculose que contraiu no sistema prisional e da qual ainda se recupera apropriadamente" (Parecer D) e "Disse que hoje não se encontra muito bem, pois sofre de dores de cabeça quando sente muita raiva e desejo de vingança com o mundo" (Parecer F).

A categoria "Dificuldade financeira ou de inserção no mercado de trabalho", por último, agrupou todas as informações relatadas sobre estar-se vivendo sérias dificuldades financeiras depois de ter saído da prisão, em condições socioeconômicas precárias, ou então em dificuldades para conseguir um emprego formal por conta do estigma da condição de ser ex-presidiária. Neste sentido, os pareceres D, “(...) referiu que sofre preconceito por ser egressa do sistema penal, o que a desestimula bastante, e que (...) tudo no que queria pensar e gostaria de obter seria um emprego fixo" e F, “(...) referiu que se encontra desesperada porque não consegue um emprego". Este dito sentimento de desespero com o desemprego foi encontrado em dois pareceres.

Os relatos encontrados sobre as vivências ao longo da trajetória de vida destas mulheres, do início de suas vidas até a prisão e depois dela, se encontram, em grande parte, em concordância com o que já traz a literatura. Assim, Souza et al. (1998) ressaltaram a existência do perigo de contágio de várias enfermidades na prisão, Carvalho et al. (2006) e Cerneka (2009) enfatizaram a solidão da mulher privada de liberdade, que recebe menos visitas que os homens, gerando o sentimento de abandono, Frinhani e Souza (2005) chamaram a atenção para a recorrência do trabalho como domésticas, Carvalho et al (2006) e Huang et al. (2012) para o histórico de educação deficitária e Barcinski (2009) para o aliciamento ou forte influência de companheiros e demais figuras masculinas para aquela mulher envolverse com o tráfico.

\section{Discussão}

O que o conjunto dos resultados apresentados deflagrou é a inegável 
exposição da situação de vulnerabilidade e marginalidade sociais vividas pelas mulheres da amostra, bem como o ciclo de violências iniciado desde a infância: um cenário de abandono parental, trabalho infantil, abuso sexual e relacionamentos abusivos, influência ou aliciamento por homens para a participação nos crimes, solidão e abandono no cárcere, problemas de saúde, desemprego e condição financeira precária após a prisão.

As mulheres, enquanto integrantes do gênero feminino, são conhecidamente submetidas a um ciclo contínuo de violências ao longo de suas vidas, físicas ou não, estruturais, simbólicas ou institucionais. Quando falamos de mulheres de classes oprimidas, as violências se tornam ainda mais comuns e mais intensificadas e as acompanham do início de suas vidas até o final. São histórias de violência e de falta de acesso aos direitos de cidadania, aos bens e aos benefícios da sociedade que garantem a dignidade humana.

Esse foi o tom das histórias presentes nos pareceres das mulheres que compuseram este estudo. Quando elas foram presas, esse ciclo de violência continuou e ganhou expressão, principalmente, na solidão vivenciada dentro daqueles muros, bem como a aquisição de problemas de saúde. Neste sentido, a prisão, por si mesma, funciona como uma dupla penalização: além da condenação à pena privativa de liberdade em si mesma, as mulheres também são penalizadas, como ressaltaram Carvalho et al. (2006), com a solidão, algo que decorre especificamente da condição de ser mulher, uma vez que isso ocorre menos para a população carcerária masculina, que recebe mais visitas, inclusive visita íntima. A mulher presa, por diversos motivos, é condenada ao esquecimento e ao abandono familiar e conjugal, e isto foi o levantado nas análises dos pareceres deste estudo.

As estratégias de resistência relatadas parecem ser o único respiro no meio da sequência de violências. Os pareceres revelaram que a aproximação com a religião (a evangelização), a realização de cursos e também o trabalho foram as formas encontradas para sobreviver à prisão e "ocupar a cabeça", ou promover saúde mental e, por que não, física. A oportunidade de fazer cursos foi também uma maneira de resistir e se ocupar. De fato, tratam-se de uma forma de fazer o tempo deixar de ser 
apenas um tempo de espera para ser também de produção.

O ciclo da violência continua, nos dizem os pareceres, igualmente após o cárcere. A dupla penalização referida segue para fora da prisão sob a forma de sequelas que ela deixa na saúde. A pena de privação de liberdade é acrescida de um plus de punição que está presente nas condições estruturais, assistenciais e sanitárias precárias dos presídios que deixam danos na saúde, física e psicológica, dos sujeitos que foram presos. Um dos pareceres da amostra relatou a aquisição de tuberculose na prisão, uma enfermidade comum neste âmbito (Machado et al., 2016). Além disso, foram comuns os sintomas de sofrimento psíquico: ansiedade e depressão, insônia, traumas, sentimentos de medo, desespero, raiva e vingança.

A situação financeira precária depois do tempo em privação mais a não inserção no mercado de trabalho finalizam o conto dessa história de vulnerabilidades das mulheres. Enquanto que a situação socioeconômica já poderia ser precária nas suas vidas pregressas, inclusive possivelmente pela falta de trabalho formal em alguns casos, a dificuldade de conseguir um emprego após o cárcere, pelo estigma, contribui diretamente para a manutenção dessa situação de exclusão social.

Como bem explicaram Rosendo et al. (2018), esse cenário piora para as mulheres em relação ao homem expresidiário devido, mais uma vez, a dupla penalização: dessa vez, por aquela mulher ter fugido ao padrão de docilização e disciplinarização esperado mais delas, de maneira que é ainda menos aceitável que uma mulher, que deveria representar o arquétipo da mãe, tenha se envolvido com o crime. Se as ofertas de emprego poderiam, por diversas razões, já ser poucas antes (ou até inexistentes), depois da prisão se reduzem ainda mais.

A aquisição de um emprego, socialmente, além de meio para perceber o capital imediato de satisfação das necessidades básicas, também é uma forma de reconhecer que aquela pessoa que reconquistou a liberdade não está mais envolvida com a criminalidade (Souza e Silveira, 2017). A desocupação depois da prisão, por tais motivos, pode abrir uma porta para que se enxergue na criminalidade, novamente, a única saída restante para a obtenção de capital para a 
subsistência, levando à reincidência criminal.

Todo este cenário exposto descortina, somando-se ao conjunto de trabalhos neste campo, a falência do sistema prisional em seus (ditos) fins de recuperação da pessoa que cometeu o crime e também revela a dupla penalização imposta aos reclusos que ultrapassa, e muito, a mera reclusão. A questão é ainda mais sensível para as mulheres, que, com frequência, incorrem no crime por aliciamento de alguma figura masculina próxima, sofrem com o abandono familiar quando no cárcere e com um maior estigma decorrente da condição de ex-presidiária quando saem dele - e, consequentemente, com maior dificuldade de inserção no mercado de trabalho.

\section{Considerações finais}

O presente estudo revelou, por meio da leitura atenta dos pareceres, uma história de mulheres egressas do sistema prisional atravessada por vulnerabilidades sociais e por um ciclo de violências que pode ter início com o abandono pelos pais na infância e terminar com a condição socioeconômica precária e exclusão do mercado de trabalho depois da prisão. A análise dos dados revelou um triste padrão comum, que, inclusive, pode parecer estereotipado, mas que foi efetivamente encontrado.

Evidentemente, trata-se de uma amostra pequena e de um instrumento de coleta de informações (pareceres psicossociais) com dados prédeterminados e feitos por outrem, não tendo sido a pesquisa feita diretamente com as pessoas, de maneira que certamente nem tudo o que foi dito encontra-se nos documentos e também não se pode assegurar que o que foi registrado foi dito exatamente como foi anotado. Além disso, certamente, as dificuldades identificadas nos pareceres não devem ter sido as únicas vividas. Ainda assim, os dados relatados, que são oficiais e foram fruto de entrevistas, de fato trazem tal realidade, a qual só denuncia a condição precária das mulheres que vão presas em nosso país.

Esta realidade ressalta que alternativas para a trajetória destas mulheres são cogentes. Há uma verdadeira necessidade de adoção de penas alternativas à prisão, especialmente quando o crime é dito de 
menor potencial ofensivo. Além disso, é imprescindível promover a qualificação profissional intramuros, bem como a realização de parcerias com empresas (públicas e privadas) para incentivar e oferecer postos de trabalho (não precarizados, vale salientar) às mulheres egressas do sistema. Como lembra Baratta (1999), não se pode alcançar a reintegração social do condenado por meio do cumprimento da pena de reclusão, no entanto, se deve buscá-la apesar dela.

\section{Referências}

Assis, Simone Gonçalves; Constantino, Patrícia (2001), Filhas do Mundo: Infração Juvenil no Rio de Janeiro. Rio de Janeiro: Editora Fiocruz.

Baratta, Alessandro (2002), Criminologia crítica e crítica do Direito Penal. Introdução à Sociologia do Direito Penal [ $3^{\mathrm{a}}$ ed.]. Tradução de Juarez Cirino dos Santos. Rio de Janeiro: Revan.

Baratta, Alessandro (1999), "Paradigma do gênero: da questão criminal à questão humana", in Carmen Hein de Campos (org.), Criminologia e feminismo. Porto Alegre: Editora Sulina, p. 19-80.

Barcinski, Mariana (2009), "Protagonismo e vitimização na trajetória de mulheres envolvidas na rede do tráfico de drogas no Rio de Janeiro". Ciênc. saúde colet., 14(2), 577-586. Consultado a 02.12.2018, em https://www.scielosp.org/pdf/csc/2009.v $\underline{14 \mathrm{n} 2 / 577-586}$

Bardin, Laurence (2011), Análise de Conteúdo. São Paulo: Edições 70.

Santos, Thandara (org.) (2017). Levantamento Nacional de Informações Penitenciárias. INFOPEN - junho de 2016. Brasília: Ministério da Justiça e Segurança Pública. Departamento Penitenciário Nacional, Consultado a 10.12.2018, em http://depen.gov.br/DEPEN/noticias$\underline{\text { 1/noticias/infopen-levantamento- }}$ nacional-de-informacoes-penitenciarias2016/relatorio_2016_22111.pdf

Buglione, Samantha (2007), “O dividir da execução penal: olhando mulheres, olhando diferenças", in Salo Carvalho 
(org.), Crítica à execução penal. Doutrina, jurisprudência e projetos legislativos. Rio de Janeiro: Lumen Juris, 123-144.

Cerneka, Heidi Ann (2009), "Homens que menstruam: considerações acerca do sistema prisional às especificidades da mulher". Veredas do Direito, 6(11), 6178. Consultado a 11.12.2018, em https://heinonline.org/HOL/LandingPag e?handle=hein.journals/rveredire6\&div $=7 \& \mathrm{id}=$ \&page $=$

Cortina, Monica Ovinski de Camargo (2015), "Mulheres e tráfico de drogas: aprisionamento e criminologia feminista", Revista Estudos Feministas, 23(3), 761-778. Consultado a 11.12.2018, em http://www.scielo.br/pdf/ref/v23n3/010 4-026X-ref-23-03-00761.pdf

Cunha, Manuela Ivone Paredes Pereira da (1994), Malhas que a reclusão tece. Questões de identidade numa prisão feminina. Lisboa: Gabinete de Estudos Jurídico-Sociais.

Cunha, Manuela Ivone Paredes Pereira da (1996), “O corpo recluído: controlo e resistência numa prisão feminina", in Miguel Vale de Almeida (org.), Corpo presente: treze reflexões antropológicas sobre o corpo. Oeiras: Celta Editora, 7286.

Denzin, Norman (2017), The research act: A theoretical introduction to sociological methods. New York: Routledge.

Fausto, Boris (2001), Crime e cotidiano: a criminalidade em São Paulo (18801924) [2a ed.]. São Paulo: Edusp.

Fiorelli, José Osmir; Mangini, Rosana Cathya Ragazzoni (2017), Psicologia jurídica. [7 $7^{\mathrm{a}}$ ed.]. São Paulo: Atlas.

Fonseca, Karina Prates (2006), "Re(pensando) o crime como uma relação de antagonismo entre seus autores e a sociedade". Psicol., Ciênc. Prof. (Impr.), 26(4), 532-547. Consultado a 21.02.2019, em http://pepsic.bvsalud.org/pdf/pcp/v26n4 /v26n4a02.pdf

Frinhani, Fernanda de Magalhães Dias; Souza, Lídio de (2005), "Mulheres encarceradas e espaço prisional: uma 
análise de representações sociais". Psicologia: teoria e prática, 7(1), 61-79. Consultado a 24.02.2019, em http://pepsic.bvsalud.org/pdf/ptp/v7n1/v 7n1a06.pdf

Gonçalves, José Artur Teixeira; Madrid, Daniela Martins (2010), "Religião e crime organizado: Apropriações do privado no interior dos presídios brasileiros". Revista Intertem@s, ano XI, 19(19), 1-8. Consultado a 11.12.2018, em

http://intertemas.toledoprudente.edu.br/i ndex.php/Direito/article/view/2680/249 $\underline{7}$

Guedes, Marcela Ataide (2006), "Intervenções psicossociais no sistema carcerário feminino". Psicol., Ciênc. Prof. (Impr.), 26(4), 558-569. Consultado a 24.02.2019, em https://www.redalyc.org/pdf/2820/2820 21750004.pdf

Guimarães, Cristian Fabiano et al. (2006), "Subjetividade e estratégias de resistência na prisão. Psicol., Ciênc. Prof. (Impr.)", 26(4), 632-645. Consultado a 21.02.2019, em https://dialnet.unirioja.es/descarga/artic $\underline{\text { ulo/6156255.pdf }}$

Huang, Kaibin et al. (2012), The Significance of Breastfeeding to Incarcerated Pregnant Women: An Exploratory Study. Birth, 39(2), 145155. Consultado a 10.12.2018, em https://onlinelibrary.wiley.com/doi/abs/ 10.1111/j.1523-536X.2012.00528.x

Instituto Igarapé (2019), "Depois da prisão: caminhos possíveis para mulheres. Página consultada a 05.05.2019, em: https://igarape.org.br/depois-da-prisao/.

Lombroso, Cesare; Ferrero, Guglielmo (2004), Criminal woman, the prostitute, and the normal woman. Tradução de Nicole Hahn Rafter e Mary Gibson. Durham: Duke University Press.

Machado, Jean Carlos et al. (2016), “A incidência de tuberculose nos presídios brasileiros: revisão sistemática”. Rev. Aten. Saúde, 14(47), 84-88. Consultado $\begin{array}{lll}\text { a } & 17.03 .2019, & \text { em }\end{array}$ http://seer.uscs.edu.br/index.php/revista _ciencias_saude/article/view/3256/pdf 
Minayo, Maria Cecília de Souza (2004), O desafio do conhecimento: pesquisa qualitativa em saúde [ $8^{\text {a }}$ ed.]. São Paulo: Hucitec.

Rosendo, Juliana Vital et al. (2018), "Mulheres no cárcere: Breves reflexões sobre o sistema punitivo em Sergipe e os desafios da reinserção social”. Interfaces Científicas-Humanas e Sociais, 7(1), 107-117. Consultado a 11.12.2018, em https://periodicos.set.edu.br/index.php/h $\underline{\text { umanas/article/view/4506/2888 }}$

Shamai, Michael; Kochal, Rinat-Billy (2008), "Motherhood starts in prison: the experience of motherhood among women in prison". Family process, 47(3), 323-340. Consultado a 18.03.2019, em https://onlinelibrary.wiley.com/doi/abs/ $\underline{10.1111 / \mathrm{j} .1545-5300.2008 .00256 . x}$

Soares, Bárbara Musumeci; Ilgenfritz, Iara (2002), Prisioneiras: vida e violência atrás das grades. Rio de Janeiro: Garamond.

Soares, Gabriela Pinheiro et al. (2014), "Teatro-menor: cartografia em arte e experimentação de mulheres em situação de cárcere”. Psicologia \& Sociedade, 26, 89-99. Consultado a 03.03.2019, em https://www.redalyc.org/pdf/3093/3093 31565010.pdf

Souza, Lídio de et al. (1998), "Direitos humanos e representação de justiça". Psicologia: Reflexão e Crítica, 11(3). Consultado a 05.05.2019, em https://www.redalyc.org/pdf/188/18811 309.pdf

Zaffaroni, Raúl Eugenio (1991), Em busca das penas perdidas: a perda de legitimidade do sistema penal. Tradução de Vania Romano Pedrosa e Amir Lopez da Conceição. Rio de Janeiro: Revan 